\title{
Correction to: Pedagogical Considerations for Designing Automated Grouping Systems: The Case of the Parabola
}

\author{
Rotem Abdu $^{1}$ (D) Shai Olsher ${ }^{1} \cdot$ Michal Yerushalmy $^{1}$
}

Published online: 20 October 2021

(c) Springer Nature Switzerland AG 2021

\section{Correction to: Digital Experiences in Mathematics Education https://doi.org/10.1007/s40751-021-00095-7}

There were some data missing in the funding section. The Acknowledgements should state the following text:

This research was supported by the Yuval Ne'eman fellowship from the Israeli Ministry of Science and the Israeli Scientific Foundation (ISF) (grant 147/18).

The original article has been corrected.

Publisher's Note Springer Nature remains neutral with regard to jurisdictional claims in published maps and institutional affiliations.

The original article can be found online at https://doi.org/10.1007/s40751-021-00095-7.

Rotem Abdu

rotem_abdu@yahoo.com

1 University of Haifa, Haifa, Israel 